\title{
Nausea and Vomiting During the First 24 Hours After Chemotherapy
}

National Cancer Institute

\section{Source}

National Cancer Institute. Nausea and Vomiting During the First 24 Hours After

Chemotherapy. NCI Thesaurus. Code C107513.

Nausea and vomiting occurring during the first 24 hours following chemotherapy. 